Article

\title{
The Verification of the Degree of Concordance of the SMI/CVMS Indexes in Evaluating the Pubertal Growth Stages-Longitudinal Study
}

\author{
Elena Galan ${ }^{1}$, Andreea Raluca Hlatcu ${ }^{1}$, Ștefan Milicescu, Jr. ${ }^{2}$, Elina Teodorescu ${ }^{1}{ }^{*}$, Simina Neagoe $^{3}$ \\ and Ecaterina Ionescu 1
}

check for

updates

Citation: Galan, E.; Hlatcu, A.R.;

Milicescu, Ș., Jr.; Teodorescu, E.;

Neagoe, S.; Ionescu, E. The

Verification of the Degree of Concordance of the SMI/CVMS

Indexes in Evaluating the Pubertal

Growth Stages-Longitudinal Study.

Appl. Sci. 2022, 12, 2783. https://

doi.org/10.3390/app12062783

Academic Editors: Joseph Nissan and Gavriel Chaushu

Received: 6 February 2022

Accepted: 7 March 2022

Published: 8 March 2022

Publisher's Note: MDPI stays neutral with regard to jurisdictional claims in published maps and institutional affiliations.

Copyright: (C) 2022 by the authors. Licensee MDPI, Basel, Switzerland. This article is an open access article distributed under the terms and conditions of the Creative Commons Attribution (CC BY) license (https:// creativecommons.org/licenses/by/ $4.0 /)$.
1 Department of Orthodontics and Dentofacial Orthopaedics, Faculty of Dental Medicine, Carol Davila University of Medicine and Pharmacy, 050474 Bucharest, Romania; elena.galan@umfcd.ro (E.G.); andreea.hlatcu@umfcd.ro (A.R.H.); ecaterina.ionescu@umfcd.ro (E.I.)

2 Department of Dental Aesthetics, Faculty of Dental Medicine, Carol Davila University of Medicine and Pharmacy, 050474 Bucharest, Romania; stefan.milicescu@umfcd.ro

3 Department of Periodontology, Faculty of Dental Medicine, Titu Maiorescu University, 031593 Bucharest, Romania; chelarescu.simina@yahoo.com

* Correspondence: elina.teodorescu@umfcd.ro

\begin{abstract}
The research aims to verify the concordance between the skeletal maturity index (SMI) measured on the hand and wrist $X$-rays using Fishman method and the cervical vertebral maturation stage (CVMS), measured on the lateral cephalometric X-rays using Baccetti method. The concordance of the two indexes (SMI and CVMS) has been statistically verified with the help of the Cohen's kappa coefficient, by relating them to the growth stages, within a longitudinal study done upon a group of 38 patients, 22 female and 16 male, aged between $8-18 \mathrm{y}$, the analyzed investigations being done in series, along the orthodontic treatment. The research showed a strong correlation between the SMI and CVMS indexes within the analyzed group, confirmed by the obtained values $(\mathrm{k}=0.84$ for female and $\mathrm{k}=0.85$ for male).
\end{abstract}

Keywords: cervical vertebra maturation stage; chronological age; biological age; hand-wrist maturation; skeletal maturity index

\section{Introduction}

The individual growth variations, observed at patients with the same chronological age, for both sexes, within the same family and even at dizygotic twins, led to the developing of the concept of biological age, which defines the path followed until reaching the individual maturity.

Out of all the indicators of the biological age, the skeletal age is considered by most authors as having the best accuracy. Determining the skeletal age using a hand X-ray is the consecrated method and in the specialty literature there are numerous studies done upon different population groups, which shows it value and its applicability at a large scale [1-5].

On the other hand, estimating the skeletal age by using the development of the cervical vertebrae is a rather recent method, compared to the use of the hand and wrist X-rays. This method gained many supporters, the motive of its popularity being the fact that the interpretation is being done on the lateral cephalogram, a routine investigation within the orthodontic treatment, thus requiring no additional exposure of the patients to any other X-rays [6,7].

During the last decades, due to the popularization of the evaluation methods of the skeletal age through the analysis of the cervical vertebrae on the lateral cephalograms, the doctors' interest in the analysis of the cervical region on lateral X-rays increased. There were authors who showed that the lateral cephalograms could be useful for evaluating the natural position of the head [8]. Furthermore, some associations were found between 
cervical vertebrae anomalies, such as the appearance of fusion in the cranio-facial syndromes and dental malocclusions [9]. Given the context of the existing correlation between malocclusion development at the level of the dento-maxillary apparatus and the development of the cervical vertebrae, there rises the legitimate question whether the CVMS indexes keep their validity during the orthodontic treatments that aim to correct the dentomaxillary anomalies.

There exist in the specialty literature a series of studies that confirm the existing correspondence between the CVMS and SMI indexes during the stages of the pubertal growth [1-7,10-30].

Objectives:

Prior to this study, a transversal study was done upon a group of 150 subjects (89 female and 61 male), aged between 8-18 y. Given the existing data in the specialty literature and the average age for reaching the skeletal maturity index SMI and cervical vertebral maturation stage CVMS within the researched group, a hypothesis was formulated, regarding the correspondence between the SMI and CVMS stages during the pubertal growth (Table 1) [23].

Table 1. Correspondence of the SMI and CVMS indexes according to the stages of growth and development.

\begin{tabular}{ccc}
\hline Growth Stage & SMI & CVMS \\
\hline Pre-pubertal stage & $1,2,3,4$ & 1,2 \\
\hline Pubertal stage & $5,6,7$ & 3 \\
\hline Post-pubertal stage & $8,9,10,11$ & 4,5 \\
\hline
\end{tabular}

This hypothesis was statistically checked using the Cohen's kappa coefficient and the results ( $k=0.82$ for the female and $k=0.67$ for the male) confirmed the concordance of the SMI and CVMS indexes within the analyzed group and validated the correspondence hypothesis that has been formulated.

Starting with this hypothesis, the present study aimed to verify this hypothesis within a longitudinal retrospective study, done upon a selected group, for which serial investigations were done along the orthodontic treatment. The results of the two studies were subsequently compared.

Proving the correspondence of the SMI/CVMS indexes for a group of patients undergoing an orthodontic treatment would confirm the clinical applicability of these indexes along the treatment.

For realizing this study, the approval of the Committee for Research Ethics was received, as the study used existing investigations from previously created data bases [23].

\section{Materials and Methods}

The hypothesis was verified upon a mixed group of selected children and youths from Bucharest city and the adjacent area, comprised of 38 patients, 22 female and 16 male, aged between $8-18 \mathrm{y}$. The patients included in the group had dento-maxillary anomalies and had ongoing orthodontic treatments. The children from the research group had a good general health state, with no severe hormonal or growth problems.

The final group is the result of a selection, for each of the participants in this retrospective study, of several moments of growth being investigated, in most cases 2 or 3 moments that were indicated by the therapeutic necessities. The investigations were not done periodically, at previously determined fixed dates. Within the analyzed investigation there were included X-rays showing different moments of evolution, quantified by the existence of some SMI and CVMS indexes with different values between the moments caught on the radiological film.

A number of 59 sets of investigations were analyzed for the female (including a hand and wrist X-ray and a lateral cephalogram done at the same moment) and 44 sets for the male. 
Each participant in the study had at least 2 sets of investigations done, with a maximum of 5 sets, having one case with 5 sets for the female and one case with 5 sets for the male. The sets with 5 X-rays belong to patients with delays in the growth process, with treatments started at a young age and extended over a long period of time, as the parents wanted the cases resolved with no extractions and without having orthognatic surgery.

Out of the 22 female patients, 13 had 2 sets of investigations done, 4 had 3, and, respectively, 4 sets and 1 female had 5 sets of investigations.

Out of the 16 male patients included in the study group, 8 had 2 sets of investigations, 5 had 3, 2 had 4, and 1 had 5 serial investigations.

For each participant in the study, the hand and wrist X-rays were analyzed using Fishaman method [4] and the lateral cephalograms were analyzed using Baccetti method [7]. All the analyzed X-rays were done at the same radiology center, in order to rule out the possible errors that could occur during the investigations. For this study, a number of 206 X-rays were analyzed, 103 hand X-rays, and 103 lateral cephalograms, on which the SMI and CVMS indexes were determined. One month apart, all the X-rays were reanalyzed, by the same examiner, under identical conditions to verify intraoperative repeatability. Later on, the correspondence between the SMI and CVMS indexes and the stages of the pubertal growth was analyzed and the existing correspondence was statistically evaluated:

- $\quad$ The pre-pubertal stage has as corresponding indexes-SMI 1,2,3,4 and CVMS 1,2

- $\quad$ The pubertal stage, in which occurs the peak moment of growth, has as corresponding indexes-SMI 5,6,7 and CVMS 3

- $\quad$ The post-pubertal stage has as corresponding indexes-SMI 8,9,10,11-CVMS 4,5.

The emitted hypothesis was statistically verified with the help of the Cohen's kappa coefficient, after the conversion was done in the 3 phases for each SMI and CVMS stage.

For the storing and statistical analysis of the data, there was used the Excel program in the Microsoft Office Professional plus 2016, to which the Real Statistics Resource pack was added.

The collected data was statistically analyzed in a descriptive way and three statistical analyses were done for the verification of the hypothesis:

- The Pearson parametric correlation test, in order to see the degree of association of the obtained values

- $\quad$ The $t$ test for pair measurements, in order to see whether there exist any systematical errors within the analyzed data

- $\quad$ The Cohen's kappa coefficient.

\section{Results}

To assess the intra-operator repeatability, the collected data was checked by using the Cohen Kappa coefficient and the results obtained by the two measurements, done successively, one month apart by the same examiner under identical conditions, showed a perfect or almost perfect concordance $(\mathrm{k}=0.972$ for the skeletal maturity index SMI and $\mathrm{k}=0.955$ for the cervical vertebral maturation stage CVMS), which allowed the data to be used within the study.

In the diagrams in the Figures 1 and 2, there is a presentation of the percentage distribution of the number of serial investigation sets within the two groups.

In the diagrams in the Figures 3 and 4, one can see for the study group the distribution of the analyzed X-rays according to age for the two sexes. A large number of investigations were done in order to capture the modifications that occur in the growth process connected to the pubertal period.

At the statistical analysis of the data, the Pearson parametric test confirms the existence of a strong correlation between the data analyzed for both groups $(r=0.94)$. The obtained value was higher in the case of both sexes in comparison to the one obtained in the transversal study. The results of the $t$ tests for pair measurements confirmed the absence of systematic errors. The values obtained for the Cohen's kappa coefficient show the existence 
of an almost perfect concordance for both sexes. For female, the value was $\mathrm{k}=0.84$ and for male $\mathrm{k}=0.85$ (Tables 2 and 3 ).

The percentage distribution of the number of analyzed investigation sets within group of female

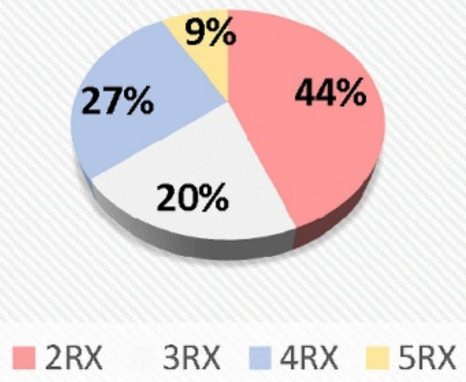

Figure 1. The percentage distribution of the number of analyzed investigation sets within the group of females. Out of the 59 sets of investigations, $44 \%$ had 2 sets of investigations done, $20 \%$ had 3 sets, $27 \%$ had 4 sets, and $9 \%$ had 5 sets (in the diagram $2 R X, 3 R X, 4 R X$, and $5 R X$ represents the number of sets of radiological investigations).

The percentage distribution of the number of analyzed investigation sets within the group of male

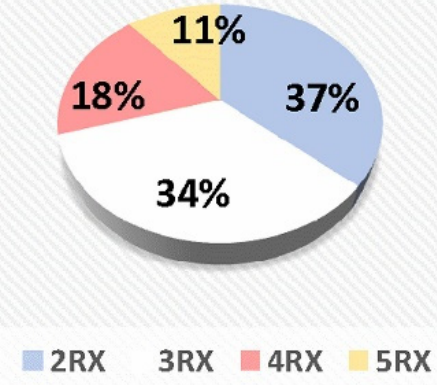

Figure 2. The percentage distribution of the number of analyzed investigation sets within the group of males. Out of the 44 sets of investigations, 37\% had 2 sets of investigations done, $34 \%$ had 3 sets, $18 \%$ had 4 sets, and $11 \%$ had 5 sets (in the diagram $2 R X, 3 R X, 4 R X$, and $5 R X$ represents the number of sets of radiological investigations).

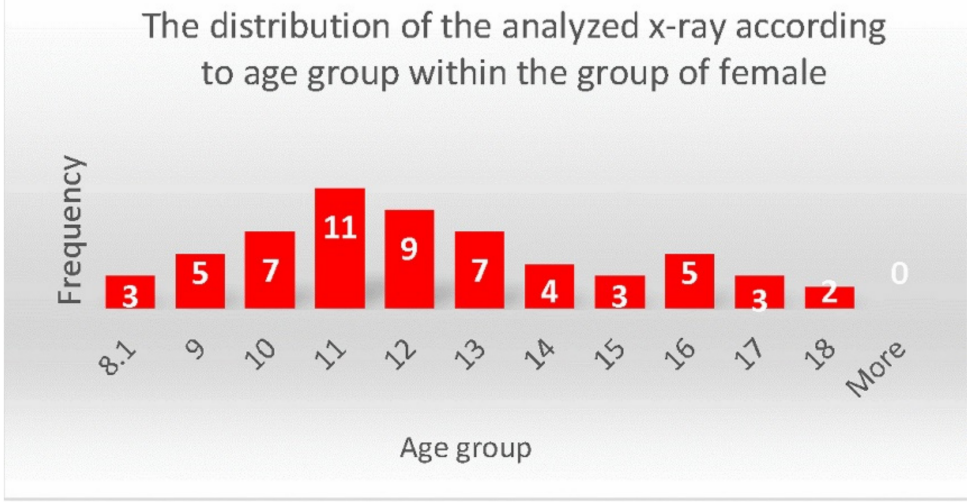

Figure 3. The distribution of the analyzed X-rays according to age groups within the group of females. 
The distribution of the analyzed $x$-ray according to age groups within the group of male

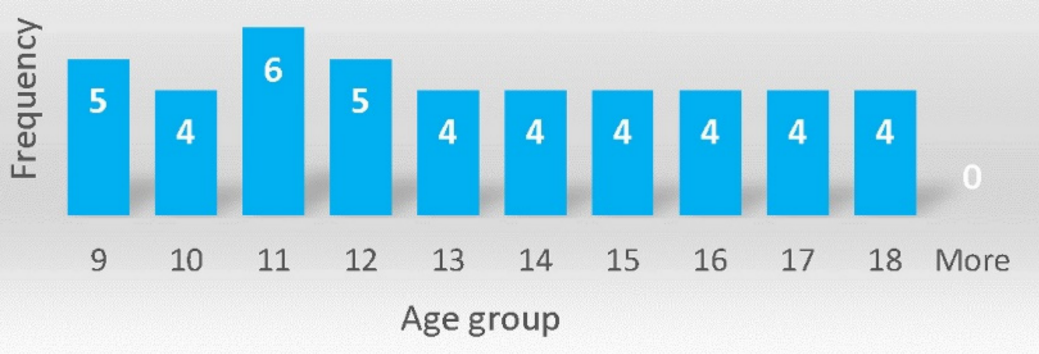

Figure 4. The distribution of the analyzed X-rays according to age groups within the group of males.

Table 2. The result of the Cohen's kappa coefficient for the group of females.

\begin{tabular}{ccccc}
\hline & & CVMS & & \\
\hline SMI & 1 & 2 & 3 & TOTAL \\
\hline 1 & 24 & 1 & 0 & 25 \\
\hline 2 & 2 & 9 & 2 & 13 \\
\hline 3 & 0 & 1 & 20 & 21 \\
\hline TOTAL & 26 & 11 & 22 & 59 \\
\hline
\end{tabular}

"1", "2" and"3" represent pre-pubertal stage, pubertal stage and, respectively, post-pubertal stage.

Table 3. The result of the Cohen's kappa coefficient for the group of male.

\begin{tabular}{ccccc}
\hline & & CVMS & & \\
\hline SMI & 1 & 2 & 3 & TOTAL \\
\hline 1 & 22 & 4 & 0 & 26 \\
\hline 2 & 1 & 1 & 0 & 2 \\
\hline 3 & 0 & 0 & 16 & 16 \\
\hline TOTAL & 23 & 5 & 16 & 61 \\
\hline
\end{tabular}

"1", "2" and"3" represent pre-pubertal stage, pubertal stage and respectively post-pubertal stage.

pa (denotes the percent agreement) -0.8983

pe (represent the Cohen's chance-agreement probability) -0.360529

$\mathrm{k}-0.840962$ a perfect or almost perfect accord.

$\mathrm{Pa}$ (denotes the percent agreement) -0.8864

pe (represent the Cohen's chance-agreement probability) -0.232196

$\mathrm{k}-0.852046$ a perfect or almost perfect accord.

The obtained values confirm the validity of the analyzed hypothesis and show the existent concordance of the SMI and CVMS indexes in the determination of the pubertal stages within the study group. The results are superior to those obtained in the transversal study, thus proving the existence of a stronger concordance between the analyzed data (Table 4) [23]. 
Table 4. Comparative analysis of the statistical data in the two studies.

\begin{tabular}{ccccc}
\hline \multirow{2}{*}{ Statistic Test } & \multicolumn{2}{c}{ Value Obtained for Females } & \multicolumn{2}{c}{ Value Obtained for Males } \\
\cline { 2 - 5 } & $\begin{array}{c}\text { Transversal } \\
\text { Study }\end{array}$ & $\begin{array}{c}\text { Longitudinal } \\
\text { Study }\end{array}$ & $\begin{array}{c}\text { Transversal } \\
\text { Study }\end{array}$ & $\begin{array}{c}\text { Longitudinal } \\
\text { Study }\end{array}$ \\
\hline $\begin{array}{c}\text { Pearson } r \\
\text { correlation test }\end{array}$ & $r=0.90$ & $r=\mathbf{0 . 9 4}$ & $r=0.87$ & $r=\mathbf{0 . 9 4}$ \\
\hline $\begin{array}{c}t \text { Test for pair } \\
\text { measurements }\end{array}$ & $p=0.57$ & $p=\mathbf{1}$ & $p=0.76$ & $p=\mathbf{0 . 1 8}$ \\
\hline $\begin{array}{c}\text { Cohen's kappa } \\
\text { coefficient }\end{array}$ & $k=0.83$ & $k=\mathbf{0 . 8 4}$ & $k=0.67$ & $k=\mathbf{0 . 8 5}$ \\
\hline
\end{tabular}

\section{Discussion}

Following the analysis, within the group of females, out of 59 evaluations, in 53 cases we found a perfect concordance; in other words, within the group of females, in 53 cases out of the 59 analyzed evaluations the SMI and CVMS indexes showed the same pubertal stage. For the males, out of the 44 evaluations, 39 were in perfect concordance. The obtained values confirm the validity of the evaluated hypothesis, the data showing a better concordance in the case of testing the hypothesis on subjects with serial investigations than in the case of the subjects from the transversal study, this being probably due to the fact that the analyzed investigations belong to the same patient in the case of the longitudinal study.

In the group of females, most discrepancies, two of each, were found at the beginning and the end of the pubertal period. The discrepancy between the pubertal and pre-pubertal stages may come from the estimation on the hand X-ray of the SMI 5 stage (indicating the pubertal stage), while the lateral cephalogram corresponds to the CVMS 1 or 2 stage (pre-pubertal stage).

The discrepancy between the pubertal and post-pubertal stages is linked to the coexistence of the CVMS 4 stage (indicating the post-pubertal stage) on the lateral cephalogram with a SMI 7 stage (pubertal stage) estimated on the hand X-ray.

In the case of the males, the main discrepancy appeared at the beginning of the pubertal stage. This originates in the co-existence of the CVMS 3 stage (indicating the pubertal stage) on the lateral cephalogram with the SMI 4 stage (pre-pubertal stage) on the hand and wrist $X$-ray. Out of the five discrepancies found, in four of them there was a co-existence of stages CVMS 3 and SMI 4. This fact strengthens the observation made in the transversal study as well, which states that for male, in some cases, the SMI 4 stage may correspond also to the period of maximum pubertal growth and not only to the pre-pubertal period. This fact is also confirmed by the study of Grave and Brown, 1976, who found a correspondence between the period of maximum pubertal growth and the SMI 4 and 5 stages [1].

For both the female and the male, the discrepancies noticed were observed nearby the pubertal stage in the intermediary phases of the growth stages, when passing from the pre-pubertal stage to the pubertal stage and from the pubertal stage to the post-pubertal one.

The main limitation of the study comes from the small number of participants, justified by the aim of reducing the radiation dosage to which the patient is exposed. When forming the group, a good homogeneity was sought in regards to the repartition of the SMI and CVMS stages.

The study verifies the correspondence of the skeletal maturity index SMI and cervical vertebral maturation stage CVMS, by referring to the stages of the pubertal age, based upon the data quoted in the specialty literature. It would have been useful to have had a clinical evaluation of the stages of the pubertal age for the subjects in the group and to refer the SMI and CVMS indexes to these stages.

The great variability of the chronologic age at which the stages of SMI and CVMS are reached as well as the recorded individual variability for reaching the pubertal period stages call for prudency in the interpretation of the results obtained. 


\title{
5. Conclusions
}

(1) The study proves the correspondence of the skeletal maturity index SMI and cervical vertebral maturation stage CVMS and confirms the validity of the hypothesis tested within the longitudinal study: The pre-pubertal stage has the corresponding indexes SMI 1,2,3,4 and CVMS 1,2. The pubertal stage has the corresponding indexes SMI 5,6,7 and CVMS 3. The post-pubertal stage has the corresponding indexes SMI 8,9,10,11 and CVMS 4,5. The Cohen's kappa coefficient shows the existence of an almost perfect concordance in the case of both sexes $(k=0.84$ for female and for male $k=0.85)$.

(2) The validation of the hypothesis within the longitudinal study supports the idea of a possible clinical applicability of the CVMS indexes for estimating the skeletal age along the treatment, after starting the use of orthodontic appliances. The results obtained show that the method could be clinically useful, offering information about the biological stage in which the patient finds himself/herself, in order for the orthodontist to be able to evaluate the remaining growth over the period of the orthodontic treatment.

(3) The comparison of the statistical data obtained in the two studies (transversal and longitudinal) showed with no exception better results within the longitudinal study, as a better concordance was found among the analyzed data.

(4) The study shows that both SMI and CVMS indexes could be used in order to determine the biological moment in which the patient finds himself/herself. For estimating the skeletal age, the orthodontist may use, as a common practice, the lateral cephalogram, which spares the patient from an additional eradiation necessary for a hand X-ray.

\begin{abstract}
Author Contributions: Conceptualization, E.G. and E.T.; Methodology, E.I.; Software, A.R.H. and S.N., Validation, E.I., E.T. and S.M.J.; Formal analysis, E.G.; Investigation, E.G.; Resources, E.G.; Data curation, E.G. and E.I.; Writing-original draft preparation, E.G.; Writing-review and editing, S.N.; Visualization, A.R.H.; Supervision, E.I.; Project administration, S.M.J. and A.R.H. All authors have read and agreed to the published version of the manuscript.
\end{abstract}

Funding: This research received no external funding.

Institutional Review Board Statement: Not applicable.

Informed Consent Statement: Informed consent was obtained from all subjects involved in the study. The study was conducted in accordance with the Declaration of Helsinki, and approved by the Ethics Committee of "Carol Davila" University of Medicine and Pharmacy (protocol code PO-35-F-03, 12 December 2019).

Data Availability Statement: Not applicable.

Conflicts of Interest: The authors declare no conflict of interest.

\section{References}

1. Grave, K.C.; Brown, T. Skeletal ossification and the adolescent growth spurt. Am. J. Orthod. 1976, 69, 611-619. [CrossRef]

2. Grave, B.; Brown, T.; Townsend, G. Comparison of cervicovertebral dimensions in Australian Aborigines and Caucasians. Eur. J. Orthod. 1999, 21, 127-135. [CrossRef] [PubMed]

3. Fishman, L.S. Chronological versus Skeletal Age, an Evaluation of Craniofacial Growth. Angle Orthod. 1979, 49, 181-187. [PubMed]

4. Fishman, L.S. Radiographic Evaluation of Skeletal Maturation: A Clinically-Orientated Method Based on Hand Wrist Films. Angle Orthod. 1982, 52, 88-112.

5. Turchetta, B.J.; Fishman, L.S.; Subtelny, D.J. Facial Growth Prediction: A Comparison of Methodologies. Am. J. Orthod. Dentofac. Orthop. 2007, 132, 439-449. [CrossRef]

6. Hassel, B.; Farman, A.G. Skeletal Maturation Evaluation Using Cervical Vertebrae. Am. J. Orthod. Dentofac. Orthop. 1995, 107, 58-66. [CrossRef]

7. Baccetti, T.; Franchi, L.; McNamara, J.A. An improved version of the cervical vertebral maturation (CVMS) method for the assessment of mandibular growth. Angle Orthod. 2002, 72, 316-323.

8. Kylamarkula, S.; Huggare, J. Head posture and the morphology of the first cervical vertebra. Eur. J. Orthod. 1985, 7, 151-156. [CrossRef] 
9. Sonnesen, L. Associations between the Cervical Vertebral Column and Craniofacial Morphology. Int. J. Dent. 2010, 295728. [CrossRef]

10. Hägg, U.; Taranger, J. Maturation indicators and the pubertal growth spurt. Am. J. Orthod. 1982, 82, 299-309. [CrossRef]

11. Grave, K.; Townsend, G. Cervical vertebral maturation as a predictor of the adolescent growth spurt. Aust. J. Orthod. 2003, $19,25-31$.

12. Grave, K.; Townsend, G. Hand-wrist and cervical vertebral maturation indicators: How can these events be used to time Class II treatment? Aust. J. Orthod. 2003, 19, 33-45.

13. Garcia-Fernandez, P.; Torre, H.; Flores, L.; Rea, J. The cervical vertebrae as maturational indicators. J. Clin. Orthod. 1998, 32, 221-225. [PubMed]

14. O'Reilly, M.; Yanniello, G.J. Mandibular Growth Changes and Maturation of Cervical Vertebrae: A Longitudinal Cephalometric Study. Angle Orthod. 1988, 58, 179-184. [PubMed]

15. Kucukkeles, N.; Acar, A.; Biren, S.; Arun, T. Comparisons between cervical vertebrae and hand-wrist maturation for the assessment of skeletal maturity. J. Clin. Pediatric Dent. 1999, 24, 47-52.

16. Franchi, L.; Baccetti, T.; McNamara, J.A., Jr. Mandibular Growth as Related to Cervical Vertebral Maturation and Body Height. Am. J. Orthop. Dentofac. Orthop. 2000, 118, 335-340. [CrossRef] [PubMed]

17. Franchi, L.; Baccetti, T.; McNamara, J.A. Postpubertal asssessment of treatment timing for maxillary expansion and protraction therapy followed by fixed appliances. Am. J. Orthod. Dentofac. Orthop. 2004, 126, 555-568. [CrossRef]

18. Chang, H.P.; Liao, C.H.; Yang, Y.H.; Chang, H.F.; Chen, K.C. Correlation of cervical vertebrae maturation with hand-wrist maturation in children, Kaoshiung. J. Med. Sci. 2001, 17, 29-35.

19. San Roman, P.; Palma, J.C.; Oteo, M.D.; Nevado, E. Skeletal maturation determined by cervical vertebrae development. Eur. J. Orthod. 2002, 24, 303-311. [CrossRef]

20. Ballrick, J.; Fields, H.; Vig, K.W.L.; Beck, F.M.; Germak, T.; Baccetti, T.; Franchi, L. Reliability and Validity of Cervical Vertebral Maturation and Hand-Wrist Radiographs. In Proceedings of the 83rd General Session of the IADR/AADR/CADR, Baltimore, MD, USA, 9-12 March 2005.

21. Flores-Mir, C.; Burgess, C.A.; Champney, M.; Jensen, R.J.; Pitcher, M.R.; Major, P.W. Correlation of skeletal maturation stages determined by cervical vertebrae and hand-wrist evaluations. Angle Orthod. 2006, 76, 1-5.

22. Manosudprasit, M.; Wangsrimongkol, T.; Pisek, P.; Chantaramungkorn, M. Comparative Study between the Hand-Wrist Method and Cervical Vertebral Maturation Method for Evaluation Skeletal Maturity in Cleft Patients. J. Med. Assoc. Thai. 2013, 96, S19-S24. [PubMed]

23. Galan, E.; Hlatcu, A.R.; Bencze, A.; Teodorescu, E.; Păcurar, M.; Chibelean, M.; Ionescu, E. Concordanţa indicilor de maturare osoasă SMI şi CVMS în etapele creşterii pubertare-Studiu transversal Ro. J. Stomatol. 2021, 67, 186-192.

24. Beit, P.; Peltomaki, T.; Schatzle, M.; Signorelli, L.; Patcas, R. Evaluating the Agreement of Skeletal Age Assessment Based on Hand-Wrist and Cervical Vertebrae Radiography. Am. J. Orthod. Dentofac. Orthop. 2013, 144, 838-847. [CrossRef]

25. Cangialosi, T.; Vives, V. Another Look at Skeletal Maturation Using Hand Wrist and Cervical Vertebrae Evaluation. Open J. Orthop. 2018, 8, 1-10. [CrossRef]

26. Gandini, P.; Mancini, M.; Andreani, F. A comparison of hand-wrist bone and cervical vertebral analyses in measuring skeletal maturation. Angle Orthod. 2006, 76, 984-989. [CrossRef] [PubMed]

27. Lai, E.H.; Liu, J.; Chang, J.Z.; Tsai, S.; Yao, C.; Chen, M. Radiographic Assessment of Skeletal Maturation Stages for Orthodontic Patients: Hand-wrist Bones or Cervical Vertebrae? J. Formos. Med. Assoc. 2008, 107, 316-325. [CrossRef]

28. Mellon, Z.J.; Behrents, R.G.; Johnston, L.E. The Pattern of Facial Skeletal Growth and Its Relationship to Various Common Indexes of Maturation. Am. J. Orthod. Dentofac. Orthop. 2013, 143, 845-854. [CrossRef]

29. Soegiharto, B.M.; Moles, D.R.; Cunningham, S.J. Discriminatory ability of the skeletal maturation index and the cervical vertebrae maturation index in detecting peak pubertal growth in Indonesian and white subjects with receiver operating characteristics analysis. Am. J. Orthod. Dentofac. Orthop. 2008, 134, 227-237. [CrossRef]

30. Wong, R.W.; Alkhal, H.A.; Rabie, B.M. Use of cervical vertebral maturation to determine skeletal age. Am. J. Orthod. Dentofac. Orthop. 2009, 136, 484.e1-e6. [CrossRef] 